\title{
Size Separation of Interstitial Water in Marine Sediments
}

\author{
Tsuneo Shiba* \\ (Received July 17, 1989)
}

\begin{abstract}
Interstitial waters of marine sediments were separated into the two portions. A large interstitial water was extracted from sediment core samples by a centrifugation at $42 \times \mathrm{g}$ for $30 \mathrm{~min}$, and then a small interstitial water was extracted at $1,500 \times \mathrm{g}$ from the residual sediment samples. The content of the large interstitial water was high in sandy sediment, while the small interstitial water was in silty and clayey sediment. Concentrations of polymeric carbohydrates were higher in the small interstitial water than in the large interstitial water, although no difference was found in monomeric carbohydrate. It was suggested that monomeric carbohydrates were uniformly distributed in marine sediments by diffusion, while polymeric carbohydrates were not.
\end{abstract}

The tension, with which interstitial water is held by sediment particles, is affected by the size of interstices. Since water mobility depends on the tension, distribution of organic matter ought to change with the size of interstices. However, chemical species have been generally determined with the waters collected by the methods of squeezing, ${ }^{1,2)}$ centrifugation, or dialysis. ${ }^{3-5)}$ of these methods, only the interstitial water collected by dialysis is suspected to be a large interstitial water, while the others should be a mixture of the waters of widely different interstice size.

In this report the distribution of the interstitial water and their carbohydrate content were examined. The interstitial waters were drained from sediment sample by centrifugation at different rotation speed. ${ }^{6)}$ The tensions, with which interstitial water is held by sediment particles, were calculated from the speed and radius of rotation. Also the size distribution of sediment particles was examined, since the distributions of the interstitial water are suspected to be dependent on sediment structure.

\section{Materials and Methods}

\section{Sampling}

Sediment samples were collected at the tidal flats of Orikasa and Uranohama in May 1985 and at Otsuchi Bay in April 1987. The water temperature in this area ranges from ca. $20^{\circ} \mathrm{C}$ in summer to 5 or $4^{\circ} \mathrm{C}$ in spring. A spade type box core sampler was used at Otsuchi bay. At the tidal flats the sediment samples were collected by driving the Phrager corer into sediment by hand. The sampling station of Orikasa was exposed only at the lowest tide, while the station of Uranohama was flooded only at high tide.

\section{Extraction of Interstitial Water}

The samples were cut into $1 \mathrm{~cm}$ sections. About ten $\mathrm{g}$ of the sections was placed on a conical support (Aminco Co.), the bottom of which was stopped with a glass fiber filter burned at $400^{\circ} \mathrm{C}$ for $1 \mathrm{~h}$. Then the conical support was covered with a parafilm having a few pinholes, placed on a centrifuge tube and centrifuged at $42 \times \mathrm{g}$ for $30 \mathrm{~min}$. Interstitial water was collected in the centrifuge tube. The drained seawater was defined as a large interstitial water. The applied tension, " $T$ ", developed by centrifugation at a point of the sediment sample, $r_{2} \mathrm{~cm}$ form the center of rotation, is given by the equation:?

$$
T=\omega^{2} \cdot\left(r_{1}^{2}-r_{2}{ }^{2}\right) / 2 g
$$

where $T$ is in centimeter of water, $\omega$ is the radial velocity in radian per second, $g$ is the acceleration due to gravity in $\mathrm{cm} / \mathrm{s}^{2}, r_{1}$ is the distance $(: 15 \mathrm{~cm})$ from the base of the sediment sample to the center of rotation. The $\mathrm{pF}$ of the large interstitial water was less than 1.9. The $\mathrm{pF}$ value ${ }^{8)}$ is the logarism to the base 10 of the numerical value of the applied tension. Since the applied tension varies across the sample in the conical support ${ }^{\theta)}$ the value at the mid point was employed for the calculation of $\mathrm{pF}$.

The sediment samples remained on the conical supports were again centrifuged at $1,500 \times \mathrm{g}$ for

* Otsuchi Marine Research Center, Ocean Research Institute, University of Tokyo, Akahama, Otsuchi Iwate 028-11, Japan（芝 恒男：東京大学海洋研究所）。 
$30 \mathrm{~min}$. The extract at this centrifugation was defined as a small interstitial water. Its $\mathrm{pF}$ value ranged from 3.4 to 1.9 . Dry weight was estimated with sediments heated at $105^{\circ} \mathrm{C}$ for 1 day.

\section{Size Distribution of Sediment Particles}

After gentle shaking in a $100 \mathrm{ml}$ of seawater for $1 \mathrm{~h}$, sediment particles were filtrated through three sieves of different pore size. The fractions of larger than $2000 \mu \mathrm{m}, 2000-250 \mu \mathrm{m}, 250-63 \mu \mathrm{m}$, and smaller than $63 \mu \mathrm{m}$ were obtained. The fractions of $2000-250 \mu \mathrm{m}$ and $250-63 \mu \mathrm{m}$ were again shaken vigorously for $1 \mathrm{~h}$ in distilled water containing a Na-hexametaphosphate ${ }^{10)}$ as a dispersant. Both the suspensions were passed through $250 \mu \mathrm{m}$ and $63 \mu \mathrm{m}$ pore size sieves. All of the fractions were heat-dried at $105^{\circ} \mathrm{C}$ for 1 day and weighed after cooling in a desiccator. The degree of flocculation in the fractions of 2000$250 \mu \mathrm{m}$ and $250-63 \mu \mathrm{m}$ was estimated by subtracting the dry weight of dispersed aggregates from the dry weight of each fraction. The particles smaller than $63 \mu \mathrm{m}$ were defined as silt and clay, those of $250-63 \mu \mathrm{m}$ were fine sand, those of $2000-250 \mu \mathrm{m}$ coarse and medium sand, and those larger than $2000 \mu \mathrm{m}$ were gravels. ${ }^{11)}$

\section{Permeability}

A $100 \mathrm{ml}$ of seawater was passed through a $10 \mathrm{~cm}$ sediment column at ca. 0.6 atmospheric pressure. The time for filtration of the water column was determined.

\section{Measurement of Carbohydrate Concentrations}

Carbohydrate concentration was determined with the interstitial waters diluted 2.5 folds with pure water prepared with ROpure-NANOpure system (The Barnstead Co. Boston). Monomeric carbohydrates were determined by the procedure of Johnson and Sieburth ${ }^{12}$ using 3-methyl-2benzothiazolinone hydrazone hydrochloride. The procedure gave a linear response down to $0.3 \mu \mathrm{g} /$ $\mathrm{m} l$. Total carbohydrates were determined after heating at $100^{\circ} \mathrm{C}$ with $0.1 \mathrm{~N} \mathrm{NCl}$ and neutralization. ${ }^{13)}$

\section{Results}

\section{Interstitial Water}

The contents of the small interstitial water were high in silty and clayey sediments. The contents ranged from 25.3 to $23.3 \%$ in the wet weight of sediment samples of Otsuchi where silt and clay particles ranged from 56.9 to $86.5 \%$, while the contents changed mainly in the range from 12.6 to $5.6 \%$ in sandy sediments of Orikasa (Fig. 1, 2). At Uranohama the small interstitial water increased with the increase of silt and clay. A clear linear relationship was obtained between the contents of the small interstitial water and the percent occurrence of silt and clay particles (Fig. 3). Although an exceptional high value was obtained at the depth of $2-3 \mathrm{~cm}$ of Orikasa, this seemed to be due to the compaction of sand particles (Fig. 4).

The contents of the large interstitial water were contrary high in sandy sediments. The contents ranged from 18.0 to $10.5 \%$ in Orikasa, while in Otsuchi the contents fallen in the range from 10.6 to $4.4 \%$. No clear linear relationship was observed between the large interstitial water and
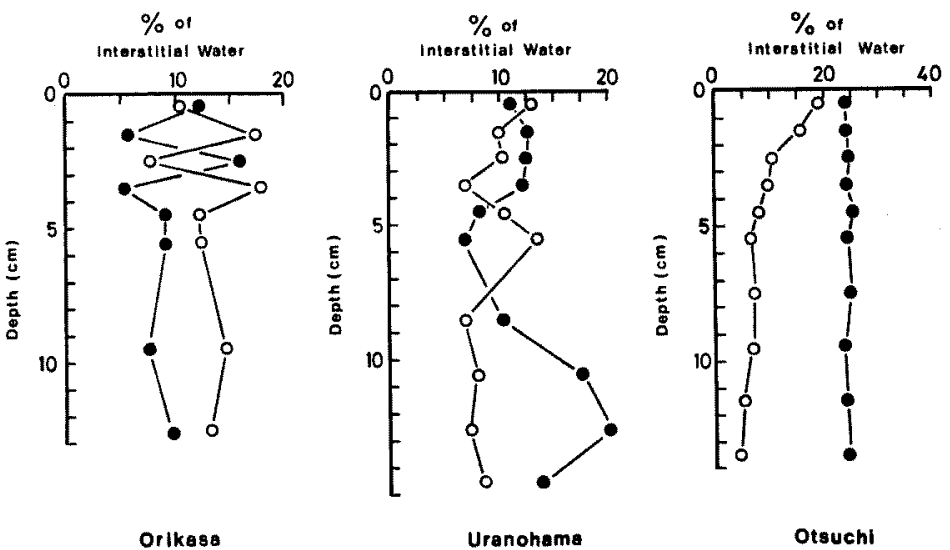

Fig. 1. Vertical profiles of the samll and the large interstitial waters. Data are plotted at the midpoint of depth intervals. Percent occurrence was based on wet weight of sediment samples. A, the small interstitial water; $\bullet$, the large interstitial water. 


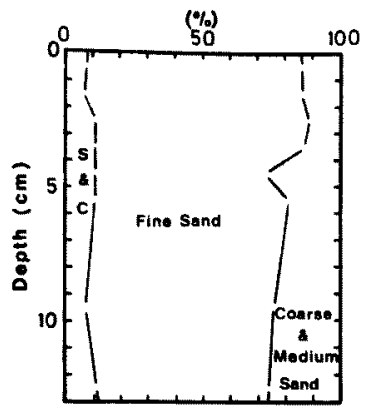

Orlkasa

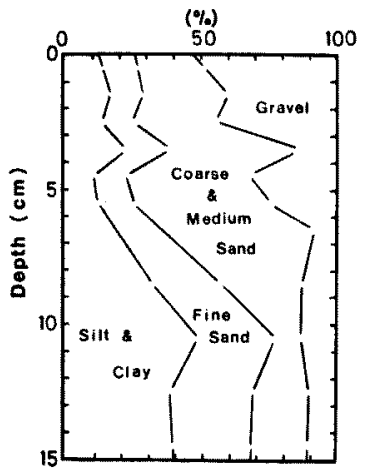

Uranohama

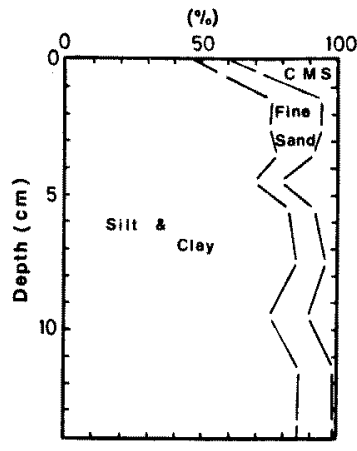

Otsuchl

Fig. 2. Size distributions of sediment particales. S\& $\mathrm{C}$, the abbreviation of silt and clay; CMS, the abbreviation of coarse and medium sand. Diameters of silt and clay are less than $63 \mu \mathrm{m}$; fine sand, 63-250 $\mu \mathrm{m}$; coarse and medium sands, 250-2000 $\mu \mathrm{m}$; gravel, more than $2000 \mu \mathrm{m}$.

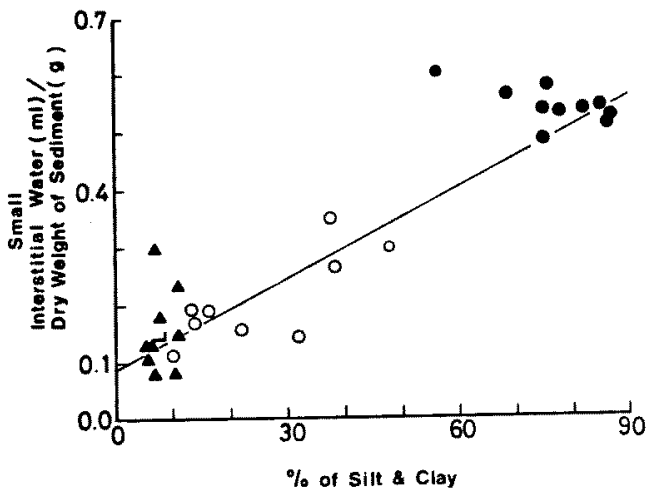

Fig. 3. Relationship between the content of the small interstitial water and the proportion of silt and clay particles. Otsuchi; $\Delta$, Orikasa; $O$, Uranohama.

sandy particles (data not shown). This can be explained by the fact that the distribution of the large interstitial water is significantly affected by the geometrical packing. The higher values, 19.0 and $15.7 \%$, in the surface layers of Otsuchi are coincided with the layer of the low aggregate contents (looser packing) (Fig. 4).

\section{Water Mobility}

Water mobility was higher in the sandy sediments of Orikasa than in the silty and clayey sediment of Otsuchi. The speed at Orikasa was more rapid than that of Otsuchi by a factor of 400 . The difference in permeability suggests different roles of these interstitial waters in marine sediments.

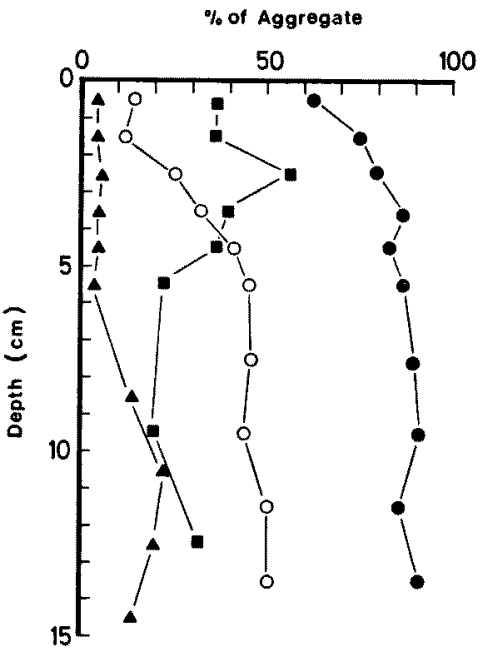

Fig. 4. Percentages of aggregates. - , in the fraction of silt and clay at Otsuchi; $O$, in the fraction of fine sand at Otsuchi; $\boldsymbol{m}$, in the fraction of fine sand at Orikasa; $\Delta$, in the fraction of coarse and medium sand at Uranohama.

Carbohydrate Content in the Small and the Large Interstitial Waters

Carbohydrate contents were examined with the samples collected at Otsuchi Bay. As shown in Figs. 5 and 6 , the total carbohydrate content ranged from 1.0 to $5.2 \mu \mathrm{g} / \mathrm{ml}$, and monomeric carbohydrate contents were in the range of 0.4 to $1.6 \mu \mathrm{g} / \mathrm{ml}$. Total carbohydrate contents were higher in the small interstitial waters than in the large interstitial waters, although no clear differences was observed in the monomeric carbohy- 


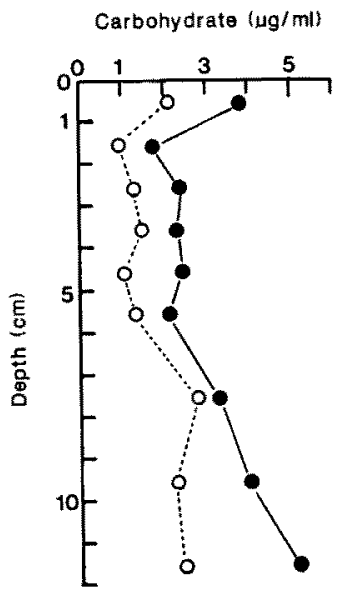

Fig. 5. Vertical profiles of total carbohydrate contents in the small and the the large interstitial water. the small interstitial water; 0 , the large interstitial water.

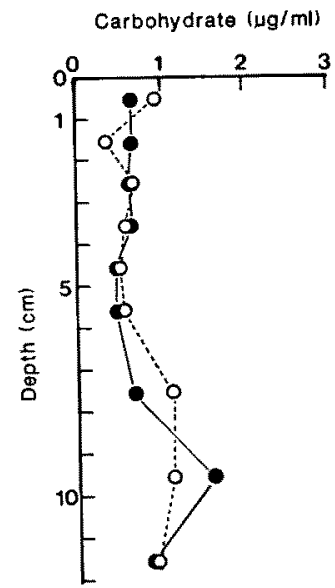

Fig. 6. Vertical profiles of monomeric carbohydrate contents in the small and the large interstitial water. 0 , the small interstitial water; 0 , the large interstitial water.

drate contents. Hence un-uniform distribution of polymeric carbohydrates is clear. Carbohydrate contents increased generally with depth, and no clear difference was found in the vertical profile between monomeric and total carbohydrate contents.

\section{Discussion}

The separation method employed in the present paper is useful for estimating each role of interstices of different size. The small interstitial water defined in this study was contained in the sediment structure of silt and clay, while the large interstitial water was relatively predominant in sandy sediments and also in loosely packed structure of silt and clay particles. Although the effects of compression, tortuosity ${ }^{14)}$ and clogging my be significant, a clear linear relationship was obtained between the small interstitial water and the particles of silt and clay. If diameter of the interstitial waters is calculated by the equation of Kohnke, ${ }^{15)}$ smallest value of the small intersitial water is $1.4 \mu \mathrm{m}$. The diameter is very close to the biotic limit of bacteria. Although carbohydrate was determined only with a single sample, the difference observed in the concentration of polymeric carbohydrate indicates the need to separate the interstitial water depending on pore size.

The ratio of solid surface area to the water volume is higher in the small interstitial water than in the large one. Since adsorbed carbohydrate content per surface area of particles has been reported not to change with the size of sediment particles, ${ }^{16,17)}$ the higher content of polymeric carbohydrate in the small interstitial water, therefore, suggests that polymeric one is selectively distributed in the water bound to sediment particles. On the other hand, an uniform distribution of monomeric carbohydrate may be explained by its higher diffusion rate. Krom and Sholkovitz ${ }^{18)}$ reported a constant concentration of low molecular weight organics in both the oxic and anoxic sediments.

The un-uniform distribution of polymeric carbohydrate can be caused by the destruction of living things during the centrigugation at higher speeds. However no ATP was detected with the extracted water even though based on the method of Niven et $a l^{19}$ ) which has a linearity down to $90 \mathrm{pg} / \mathrm{m} /$. Also monomeric carbohydrate was distributed uniformly. No. detection of ATP and an uniform distribution of monomeric carbohydrate indicated that the un-uniform distribution of polymeric carbohydrate is not an artifact.

\section{Acknowledgment}

I thank Drs. I. Koike and K. Ohwada of University of Tokyo for the comments on the manuscript. I am grateful to T. Kawamura and T. Tanaka for the help in obtaining sediment samples.

\section{References}

1) E. K. Kalil and M. Goldhaber: J. Sediment. 
Petrol., 43, 553-557 (1973).

2) J. A. Robbins and J. Gustinis: Limnol. Oceanogr., 21, 905-909 (1976).

3) R. H. Hesslein: Limnol. Oceanogr., 21, 912-914 (1976).

4) L. M. Mayer: Limnol. Oceanogr., 21, 909-912 (1976).

5) J. R. Montgomery, C. F. Zimmermann, and M. T. Price: Estuar. Coast. Mar. Sci., 9, 203214 (1979).

6) R. J. Schaffer, J. Wallace, and F. Carwood: Trans. Faraday Soc., 33, 723-734 (1937).

7) L. A. Richards and L. R. Weaver: J. Agric. Res., 69, 215-235 (1944).

8) R. K. Schofield: Trans. 3rd Intern. Congr. Soil. Sci., 2, 37-48 (1935).

9) W. M. Edmunds and A. H. Bath: Environ. Sci. Technol., 10, 467-472 (1976).

10) A. T. Buller and J. McManus: in "Estuarine and hydrography and sedimentation" (ed. by
K. R. Dyer), Cambridge Univ. Press, London, 1970 , pp. $87-130$.

11) C. K. Wentworth: J. Geol., 30, 377-392 (1922).

12) K. M. Johnson and J. M. Sieburth: Mar. Chem., 5, 1-13 (1977).

13) C. M. Burney and J. M. Sieburth: Mar. Chem., 5, 15-28 (1977).

14) G.E. Batley and M.S. Giles: Water Res., 13, 879-886.

15) H. Kohnke: Soil Physics. Mcgraw Hill, New York, 1968, pp. 17-23.

16) E. Tanoue and N. Handa: J. Oceanogr. Soc. Japan, 35, 199-208 (1979).

17) L. M. Mayer, P. T. Rahaim, W. Guerin, S. A. Macko, L. Watling, and F. E. Anderson: Estuar. Coast. Mar. Sci., 20, 491-503 (1985).

18) M. D. Krom and E. R. Sholkovitz: Geochim. Cosmochim. Acta, 41, 1565-1573 (1977).

19) D. F. Niven, P. A. Collins and C. J. Knowles: J. Gen. Microbiol., 98, 95-108 (1977). 